\title{
Wave-induced mixing and transport of buoyant particles: application to the Statfjord A oil spill
}

\author{
M. Drivdal ${ }^{1}$, G. Broström ${ }^{2}$, and K. H. Christensen ${ }^{1}$ \\ ${ }^{1}$ Norwegian Meteorological Institute, Oslo, Norway \\ ${ }^{2}$ Department of Earth Sciences, University of Gothenburg, Gothenburg, Sweden \\ Correspondence to: M. Drivdal (magnus.drivdal@met.no)
}

Received: 11 April 2014 - Published in Ocean Sci. Discuss.: 23 May 2014

Revised: 27 October 2014 - Accepted: 28 October 2014 - Published: 10 December 2014

\begin{abstract}
This study focuses on how wave-current and wave-turbulence interactions modify the transport of buoyant particles in the ocean. Here the particles can represent oil droplets, plastic particles, or plankton such as fish eggs and larvae. Using the General Ocean Turbulence Model (GOTM), modified to take surface wave effects into account, we investigate how the increased mixing by wave breaking and Stokes shear production, as well as the stronger veering by the Coriolis-Stokes force, affects the drift of the particles. The energy and momentum fluxes, as well as the Stokes drift, depend on the directional wave spectrum obtained from a wave model. As a first test, the depth and velocity scales from the model are compared with analytical solutions based on a constant eddy viscosity (i.e., classical Ekman theory). Secondly, the model is applied to a case in which we investigate the oil drift after an oil spill off the west coast of Norway in 2007. During this accident the average net drift of oil was observed to be both slower and more deflected away from the wind direction than predicted by oildrift models. In this case, using wind and wave forcing from the ERA Interim archive it is shown that the wave effects are important for the resultant drift and have the potential to improve drift forecasting.
\end{abstract}

\section{Introduction}

An important application of upper ocean models is the mixing and transport of particles, which could represent e.g., suspended sediments, plastic particles, biological matter, or oil droplets (Hackett et al., 2006). These particles are advected by the Lagrangian current, consisting of an Eulerian component, and the wave-induced Stokes drift. To take account of both the wind- and wave-induced drift components, many oil-drift models use an empirically based relation between the drift of an oil slick and the wind vector (e.g., James, 2002). This empirical rule can be stated as a simple equation for the drift of the oil, $\boldsymbol{u}_{\text {drift, }}$, as a linear function of the wind vector at $10 \mathrm{~m}$ height, $\boldsymbol{u}_{10}$, and a background ocean current, $\boldsymbol{u}_{\mathrm{BG}}$ (Reed et al., 1994):

$\boldsymbol{u}_{\mathrm{drift}}=\beta \mathbf{A} \cdot \boldsymbol{u}_{10}+\boldsymbol{u}_{\mathrm{BG}}$,

where $\beta$ is a constant and $\mathbf{A}$ is a rotation matrix determining the deflection of the wind-induced component away from the wind direction. Typically for light to moderate wind conditions, the drift speed is about $3 \%$ of the wind speed, resulting in $\beta=0.03$ with an angle of $15^{\circ}$ to the right of the wind direction in the Northern Hemisphere (Hackett et al., 2006). As the wind speed increases, waves will start to break at the surface and oil droplets are mixed into the water column. As pointed out by Reed et al. (1994), there are sea states above which the oil (even stable emulsions) will remain subsurface virtually all of the time. They find that this occurs for winds exceeding approximately $6 \mathrm{~m} \mathrm{~s}^{-1}$, resulting in an oil-drift speed of $1 \%$ of the wind speed at an angle of about $90^{\circ}$ to the right (Northern Hemisphere), instead of the $3 \%-$ $15^{\circ}$ rule that applies in lighter conditions. During oil spills, the oil that is mixed into the ocean column will consist of a range of droplets with different rise velocities depending on, for example, size and density (Johansen, 2000). The density of the oil varies greatly due to the different oil types and the complex weathering processes that oil undergoes in the ocean (Reed et al., 1999). 
An alternative to Eq. (1) is to use an ocean model to calculate the drift, but this solves only for the Eulerian component. In ocean circulation models it is common that the flux of momentum from the atmosphere is passed directly to the ocean and is related to the wind speed at $10 \mathrm{~m}$ height through a drag coefficient. In the real ocean, the wave field acts as a reservoir for momentum and energy, and a significant amount of the momentum flux from the atmosphere is taken up by the waves. The momentum flux into the ocean depends on whether the wave field is growing, in equilibrium, or decaying. Hence, the more accurate momentum flux to use for an ocean model should be the fraction of the total flux that goes directly to the currents plus the momentum lost from wave dissipation (e.g., Weber et al., 2006). These seastate-dependent momentum fluxes can be calculated from the directional wave spectrum (e.g., Saetra et al., 2007; Janssen, 2012). The difference in the momentum flux to waves and from waves will appear as a storage of momentum in the wave field; this is also known as the Stokes drift. On time scales longer than the rotational period, the Coriolis force will act on the waves and give rise to a force known as the Coriolis-Stokes force (e.g., Ursell, 1950; McWilliams et al., 1997; Polton et al., 2005; Broström et al., 2014). Directed at right angles to the direction of wave propagation (Northern Hemisphere), the Coriolis-Stokes force leads to an additional deflection of the current (i.e., Eulerian current), similar to the effect of the Coriolis force. In many cases the CoriolisStokes force can be comparable in magnitude to the standard Coriolis force, as demonstrated by e.g., Röhrs et al. (2012).

Surface wave breaking is known to enhance turbulence in the upper ocean (Craig and Banner, 1994; Agrawal et al., 1992; Gemmrich et al., 1994; Terray et al., 1996). A common way of parametrizing the influence of breaking waves in ocean models is to add a flux of turbulence kinetic energy (TKE) at the surface (Craig and Banner, 1994). The effect of wave breaking is restricted to a surface layer with a thickness of the order of the wave height (e.g., Weber, 2008). (e.g., Weber, 2008). The effective TKE flux into the ocean can be estimated from wave model data (e.g., Janssen, 2012).

Furthermore, surface waves are associated with largescale coherent structures, commonly referred to as Langmuir turbulence, which affect mixing in the upper layer (e.g., McWilliams et al., 1997; Kantha and Clayson, 2004; Harcourt and D'Asaro, 2008; D'Asaro, 2014). The interaction of the Stokes drift with the mean Eulerian flow through a vortex force gives rise to an instability known as the second Craik-Leibovich (CL2) mechanism, which causes Langmuir cells to develop (e.g., Craik, 1977; Leibovich, 1983). The effect of Langmuir circulation (LC) on the turbulence in the ocean mixed layer has been studied using large-eddy simulations (e.g., Skyllingstad and Denbo, 1995; McWilliams et al., 1997; Grant and Belcher, 2009), revealing elevated values of turbulent kinetic energy and dissipation. While the effect of wave breaking is restricted to the uppermost meters of the ocean, Langmuir turbulence affects the entire mixed layer and is more important for mixed layer deepening (e.g., Kantha and Clayson, 2004; Kukulka et al., 2010). Recent studies have shown that this mixing may impact the global climate system through modified air-sea exchanges (Belcher et al., 2012; D'Asaro et al., 2014). Stokes drift shear has been used in turbulence models as a parametrization for increased mixing when Langmuir turbulence is present (e.g., d'Alessio et al., 1998; Kantha and Clayson, 2004; Carniel et al., 2005; Janssen, 2012). However, a production term of TKE proportional to the Stokes drift shear can also be derived from generalized Lagrangian mean theory (Ardhuin and Jenkins, 2006), which is not directly related to the vortex force. In this study we include a Stokes shear production term in the main governing equations. It should be noted that more sophisticated models exist (e.g., Harcourt, 2013), but these are not tested here.

The aim of this study is to investigate the combined role of TKE injection by wave breaking, Stokes shear production, and the Coriolis-Stokes force in the drift of buoyant particles. Here the buoyant particles have constant rise velocities and can be thought of as simple representations of oil particles or plankton (such as cod eggs). The model is applied to two cases: (1) an idealized steady-state case with constant fluxes of momentum and energy, where the waves are represented by a theoretical spectrum, and (2) a specific case study where wind and wave data from the ERA Interim archive (Dee et al., 2011) are used as forcing. While the former case is well-suited for studying the impact of the various wave effects, the latter case serves as a test of the model in a practical application. For the realistic case, we consider the Statfjord A oil spill that occurred in December 2007 off the western coast of Norway. In this case, an observation of the oil slick 2 days after the accident indicates that the oil drifted with an average speed of about $0.5 \%$ of the wind speed, at an angle of around $90-120^{\circ}$ right of the wind direction, and in an eastsoutheast direction. Operational oil spill models showed a significant spread in the predicted mean trajectories and predicted faster drift speed in a more northerly direction (Hackett et al., 2009). On the other hand, the observed drift agrees better with empirical relations based on the earlier observations by Reed et al. (1994). However, these relations rely on certain threshold values of wind speed to determine both the direction and speed of the oil drift relative to the wind. While this approach might work quite well in practice (such as for the Statfjord A oil spill), it does not give much information about the physical processes involved.

The outline of this paper is as follows: in section 2 the equations of motion and the turbulence closure model are presented, including the wave-induced transport and mixing parametrizations mentioned above. The transport equation of the particles, the model, and the experiment setup are also described. In section 3 the results from the steady-state experiment (case 1) are presented and discussed. Section 4 presents the results when applying the model to the Statfjord A oil 
spill (case 2). In section 5 we present some concluding remarks.

\section{Formulation of the model components}

In the following, the $x$ axis will be defined as eastward, the $y$ axis northward, and the $z$ axis will be directed upwards. The velocity is given by $\boldsymbol{u}=u \hat{i}+v \hat{j}+w \hat{k}$, where $\hat{i}, \hat{j}$ and $\hat{k}$ denote the unit vectors in the $x, y$, and $z$ directions, respectively. Furthermore, the Eulerian velocity $\boldsymbol{u}$ will be separated into a mean part $\overline{\boldsymbol{u}}$ and fluctuating turbulent part $\boldsymbol{u}^{\prime}$. The ocean surface will be assumed to be at $z=0$.

\subsection{Sea-state-dependent fluxes}

Wave prediction models provide reliable forecasts of the directional wave spectra that can be used to obtain the seastate-dependent momentum and energy fluxes into the ocean. These fluxes depend on the shape of the directional wave variance spectrum $F$, which for deep water waves is determined by the wave energy balance equation (Komen et al., 1994):

$$
\left(\frac{\partial}{\partial t}+c_{\mathrm{g}} \cdot \nabla\right) F=S_{\mathrm{in}}+S_{\mathrm{nl}}+S_{\mathrm{d}},
$$

where $F(\omega, \theta)$ depends on the wave frequency $\omega$ and direction $\theta$, and $c_{\mathrm{g}}$ is the group velocity of the waves. The wave source terms $S_{\mathrm{in}}, S_{\mathrm{nl}}$, and $S_{\mathrm{d}}$ represent wave growth by wind, nonlinear transfer between wave components, and wave dissipation due to wave breaking/white capping, respectively. When the wave field is known from a wave model, the release of kinetic energy from wave breaking can be calculated from $S_{\mathrm{d}}$ as follows (e.g., Janssen, 2012):

$\Phi_{\mathrm{oc}}=\rho_{w} g \int_{0}^{2 \pi} \int_{0}^{\infty} S_{\mathrm{d}} \mathrm{d} \omega \mathrm{d} \theta$.

If wave spectra are not available, this energy flux can be parametrized by $\Phi_{\mathrm{oc}} / \rho_{w}=\alpha u_{*}^{3}$ (Craig and Banner, 1994), where $u_{*}$ is the water-side friction velocity and $\alpha$ a dimensionless parameter ( $\alpha=100$ is frequently used).

The momentum flux to the ocean column $\left(\boldsymbol{\tau}_{o}\right)$ consists of the flux transferred by turbulence across the air-sea interface and a flux of momentum from waves due to wave breaking and white capping. Using the source terms in Eq. (2), the effective momentum flux into the ocean may be written as (e.g., Saetra et al., 2007)

$\boldsymbol{\tau}_{o}=\boldsymbol{\tau}_{a}-\rho_{w} g \int_{0}^{2 \pi} \int_{0}^{\omega_{\mathrm{c}}} \frac{\kappa}{\omega}\left(S_{\mathrm{in}}+S_{\mathrm{d}}\right) \mathrm{d} \omega \mathrm{d} \theta$,

where $\boldsymbol{\kappa}$ is the wave number vector and $\boldsymbol{\tau}_{a}$ denotes the total atmospheric stress. It is often assumed that there is a balance between wind input and dissipation for higher frequencies than the cutoff-frequency $\omega_{\mathrm{c}}$ (Janssen, 2012), hence this is the upper limit for the integral over frequencies in Eq. (4).

\subsection{Transport equations}

For deep water waves, the Stokes drift $\boldsymbol{u}_{\mathrm{S}}=u_{\mathrm{S}} \hat{i}+v_{\mathrm{S}} \hat{j}$ can be calculated to second order in wave steepness from the wave spectral density (e.g., Jenkins, 1989):

$\boldsymbol{u}_{\mathrm{S}}=2 \int_{0}^{2 \pi} \int_{0}^{\infty} \omega \boldsymbol{\kappa} F \exp (2|\boldsymbol{\kappa}| z) \mathrm{d} \omega \mathrm{d} \theta$.

From this expression the Coriolis-Stokes force can be calculated according to $-\rho_{w} f \hat{k} \times \boldsymbol{u}_{\mathrm{S}}$, where $f$ is the Coriolis parameter. A discussion on how this force affects the mean flow can also be found in e.g., Polton et al. (2005) and in McWilliams et al. (1997). Assuming no horizontal pressure gradients and a horizontally homogeneous ocean, the horizontal Reynolds-averaged momentum equations with the Coriolis-Stokes force read

$$
\begin{aligned}
& \frac{\partial \bar{u}}{\partial t}=-v \frac{\partial^{2} \bar{u}}{\partial z^{2}}-\frac{\partial}{\partial z} \overline{u^{\prime} w^{\prime}}+f\left(\bar{v}+v_{\mathrm{S}}\right), \\
& \frac{\partial \bar{v}}{\partial t}=-v \frac{\partial^{2} \bar{v}}{\partial z^{2}}-\frac{\partial}{\partial z} \overline{v^{\prime} w^{\prime}}-f\left(\bar{u}+u_{\mathrm{S}}\right),
\end{aligned}
$$

where $v$ is the molecular viscosity and $\overline{u^{\prime} w^{\prime}}$ and $\overline{v^{\prime} w^{\prime}}$ are the Reynolds shear stresses. It has been assumed that the dominant part is related to the vertical variation. Using the Boussinesq eddy viscosity assumption, the Reynolds shear stresses are determined by

$\overline{u^{\prime} w^{\prime}}=-v_{t} \frac{\partial \bar{u}}{\partial z}, \overline{v^{\prime} w^{\prime}}=-v_{t} \frac{\partial \bar{v}}{\partial z}$.

The eddy viscosity $v_{t}$ is determined by the turbulence closure model, in this case the two-equation model described later on in Sect. 2.3. With the total momentum flux into the ocean given by Eq. (4), the boundary condition for $\overline{\boldsymbol{u}}$ at the surface is given by

$\left.\rho_{w} v_{t} \frac{\partial \bar{u}}{\partial z}\right|_{z=0}=\tau_{o}^{(x)},\left.\rho_{w} v_{t} \frac{\partial \bar{v}}{\partial z}\right|_{z=0}=\tau_{o}^{(y)}$.

In principle, the part of the momentum flux in Eq. (4) that comes from wave breaking is distributed in the upper few meters of the ocean, but the explicit form of this wave breaking stress is not known, and there is no clear consensus on how it should be distributed. However, results from Saetra et al. (2007) indicate that this has little effect on the currents, and in this study the total momentum flux is given as a boundary condition at the surface as in Eq. (8). Similar to the momentum equation, the transport equation of an active tracer quantity (such as temperature and salinity) has the form

$$
\frac{\partial \Theta}{\partial t}=-\frac{\partial}{\partial z}\left(\overline{w^{\prime} \theta}-v_{\theta} \frac{\partial \Theta}{\partial z}\right),
$$


where $\Theta$ and $\theta$ denote mean and fluctuating quantities, respectively, and $v_{\theta}$ is the molecular diffusivity. For the purpose of this study, the turbulent flux $\overline{w^{\prime} \theta}$, similar to the Reynolds shear stresses, will be modeled by an eddy diffusivity $v_{t}^{\prime}$ determined by the turbulence closure model such that

$\overline{w^{\prime} \theta}=-v_{t}^{\prime} \frac{\partial \Theta}{\partial z}$.

For the temperature equation an additional term for the solar radiation is added to Eq. (10), while the sum of latent, sensible, and long-wave radiation is treated as a flux boundary condition. For the salinity equation, precipitation acts as a source of freshwater flux. Further details on the salinity and temperature equations can be found in Umlauf and Burchard (2005).

\subsection{Turbulence kinetic energy (TKE) budget}

Including the Stokes shear production, the TKE budget for horizontally homogeneous flow becomes (e.g., Kantha and Clayson, 2004; Grant and Belcher, 2009)

$$
\begin{aligned}
\frac{\partial k}{\partial t} & =-\overline{u^{\prime} w^{\prime}} \frac{\partial \bar{u}}{\partial z}-\overline{v^{\prime} w^{\prime}} \frac{\partial \bar{v}}{\partial z}-\overline{u^{\prime} w^{\prime}} \frac{\partial u_{s}}{\partial z}-\overline{v^{\prime} w^{\prime}} \frac{\partial v_{s}}{\partial z} \\
& +\overline{w^{\prime} b^{\prime}}-\frac{\partial}{\partial z}\left(\frac{1}{2} \overline{w^{\prime}\left(u^{\prime} u^{\prime}+v^{\prime} v^{\prime}+w^{\prime} w^{\prime}\right)}+\frac{1}{\rho} \overline{w^{\prime} p^{\prime}}\right)-\varepsilon
\end{aligned}
$$

where $\varepsilon$ is the dissipation rate, and $b^{\prime}$ and $p^{\prime}$ denote the fluctuating parts of buoyancy and pressure, respectively. Assuming that the transport term (sixth term on the right hand side of Eq. 11) can be expressed by a simple gradient transport formulation, we obtain

$$
\frac{\partial k}{\partial t}=\frac{\partial}{\partial z}\left(\frac{v_{t}}{\sigma_{k}} \frac{\partial k}{\partial z}\right)+\mathcal{P}+\mathcal{P}_{\mathrm{S}}+\mathcal{G}-\varepsilon,
$$

where $\sigma_{k}$ is the turbulent Schmidt number. The terms $\mathcal{P}, \mathcal{P}_{\mathrm{S}}$, and $\mathcal{G}$ in Eq. (12) represent shear production (the two first terms on the right-hand side of Eq. 11), the Stokes shear production (third and fourth terms on the right-hand side of Eq. 11), and the buoyancy production (fifth term on the righthand side of Eq. 11). With the Boussinesq eddy viscosity assumption, the Reynolds shear stresses in Eq. (11) are determined by Eq. (7). Similarly, the buoyancy production term is modeled by the eddy diffusivity $v_{t}^{\prime}$ as follows:

$\mathcal{G}=\overline{w^{\prime} b^{\prime}}=-v_{t}^{\prime} N^{2}$,

where $N$ is the buoyancy frequency. The eddy viscosity and diffusivity are given by

$v_{t}=c_{\mu} k^{\frac{1}{2}} l, v_{t}^{\prime}=c_{\mu}^{\prime} k^{\frac{1}{2}} l$,

where $l$ is the turbulence length scale and $c_{\mu}$ and $c_{\mu}^{\prime}$ are the stability functions; these can either be constants or functions derived empirically or from a higher-order turbulence model. In a recent study by Harcourt (2013) it is shown that it may be necessary to modify the stability functions in order to take proper account of the effects of Langmuir turbulence in a two-equation turbulence model. However, this requires two more model constants, and here we will use the more traditional stability functions by Schumann and Gerz (1995). In this study, the flux of TKE defined by Eq. (3) is applied as a boundary condition at the surface, thus

$-\left.\frac{v_{t}}{\sigma_{k}} \frac{\partial k}{\partial z}\right|_{z=0}=\frac{\Phi_{o c}}{\rho_{w}}$.

In addition to solving the TKE equation (Eq. 12), we will here use a two-equation closure scheme that requires another prognostic equation to derive information about the turbulence length or time scale. Using the generic length scale (GLS) approach (Umlauf and Burchard, 2003), the second equation is for a generic parameter $\psi$. Similar to Kantha and Clayson (2004), a Stokes shear production term $\left(\mathcal{P}_{\mathrm{S}}\right)$ is added, producing the equation

$\frac{\partial \psi}{\partial t}=\mathcal{D}_{\psi}+\frac{\psi}{k}\left(c_{\psi_{1}}\left(\mathcal{P}+\mathcal{P}_{\mathrm{S}}\right)+c_{\psi_{3}} \mathcal{G}-c_{\psi 2} \varepsilon\right)$,

where $\mathcal{D}_{\psi}$ is a gradient transport term similar to Eq. (12) and $c_{\psi_{1}}, c_{\psi_{2}}$, and $c_{\psi_{3}}$ are model constants. The generic length scale $\psi$ is related to the turbulence kinetic energy $k$ and the length scale $l$ through

$\psi=\left(c_{\mu}^{0}\right)^{p} k^{m} l^{n}$,

where $c_{\mu}^{0}$ is the constant value of the stability function $c_{\mu}$ in the log layer (Umlauf and Burchard, 2003). For appropriate choices of the exponents $p, m$, and $n$, the variable $\psi$ can be directly identified with the classic length-scale-determining variables, such as in the $k-\varepsilon, k-\omega$, or $k-k l$ models (e.g., Warner et al., 2005).

Following Umlauf and Burchard (2003), the value of the mixing length at the surface is given by

$l(z=0)=L z_{0}$,

where $L$ and $z_{0}$ are constants and the source of turbulence from breaking waves has been assumed to be at $z=0$. When the length scale at the surface is given by Eq. (18), a Dirichelet boundary condition for $\psi$ can be derived from Eq. (17). The parameter $z_{0}$ is often referred to as a surface roughness length, while $L$ is often taken to be equal to the von Kármán constant (e.g., Craig and Banner, 1994). However, it is pointed out by Umlauf et al. (2003) that $z_{0}=l / L$ at $z=0$ is not related to any kind of surface roughness length; rather, it is connected to the length scale of injected turbulence, which is determined by the spectral properties of turbulence at the source. Different values of $L$ and $z_{0}$ can be found in the literature. As discussed by Rascle et al. (2012), parametrization of wave breaking through a flux boundary 
condition as in Eq. (15) is often accompanied by a large prescribed downward diffusion (by specifying values of $z_{0}$ ) in order for TKE to penetrate deep enough. Rascle and Ardhuin (2009) use $z_{0}=1.6 H_{\mathrm{S}}$ and a prescribed length scale $l=\kappa\left(z_{0}-z\right) /\left(1+\kappa\left(z_{0}-z\right) / h\right)$, where $H_{\mathrm{S}}$ is the significant wave height of the wind sea and $h$ is the mixed layer depth.

In the context of two-equation turbulence closure models, values of $z_{0}$ are usually somewhat smaller. While Umlauf et al. (2003) and Saetra et al. (2007) use $z_{0}=H_{\mathrm{S}}$, Carniel et al. (2009), who included wave breaking in the GLS approach, use a Charnok-type expression to describe $z_{0}$. Jones and Monismith (2008) find the best match with observations to be $z_{0}=1.3 H_{\mathrm{S}}$. However, Jones and Monismith (2008) use data from an area with shallow water and wave heights smaller than typical open-ocean conditions (note that for the Statfjord A case we have $H_{\mathrm{S}}$ up to $4.5 \mathrm{~m}$ ). Based on results from micro-structure temperature and conductivity measurements (Gemmrich and Farmer, 1999), Gemmrich and Farmer (2004) use $z_{0}=0.2 \mathrm{~m}$ for wave conditions where $H_{\mathrm{S}}=3.5 \mathrm{~m}$, which is more representative of the conditions during the Statfjord A oil spill. For the present study, we have found that the value of $z_{0}=0.6 H_{\mathrm{S}}$, as suggested by Soloviev and Lukas (2003), gives reasonable results. Following Umlauf et al. (2003) we use $L=0.25$.

\subsection{Particle dynamics}

In this study we consider buoyant particles with a constant prescribed rise velocity $w_{\mathrm{r}}$. The situation is analogous to the suspended sediments described by Burchard et al. (2008) except that the particles here have a positive buoyancy. The vertical distribution of the particle concentration $C$ can be described by a suspended matter equation

$\frac{\partial C}{\partial t}-\frac{\partial}{\partial z}\left(v_{t}^{\prime} \frac{\partial C}{\partial z}-w_{\mathrm{r}} C\right)=0$.

If the concentration is high enough, the mixing of particles will start to influence the TKE budget of the upper layer; in this study we will not consider such strong concentrations and instead neglect the influence of the buoyant particles on the mixing processes.

\subsection{Model and experimental setup}

The mixing model used in our experiments is the General Ocean Turbulence Model (GOTM; for a description see Umlauf and Burchard, 2005), modified to take account of the wave effects described in the previous sections. The momentum equations Eq. (6) are solved with the upper boundary conditions in Eq. (8). The turbulence closure scheme is based on the solutions of Eqs. (12) and (16), with upper boundary conditions given by Eqs. (15) and (18). For the bottom, zero flux boundary conditions are used.

In the experiments described below, the model has been run with rise velocities of $w_{\mathrm{r}}=50,100,200$, and
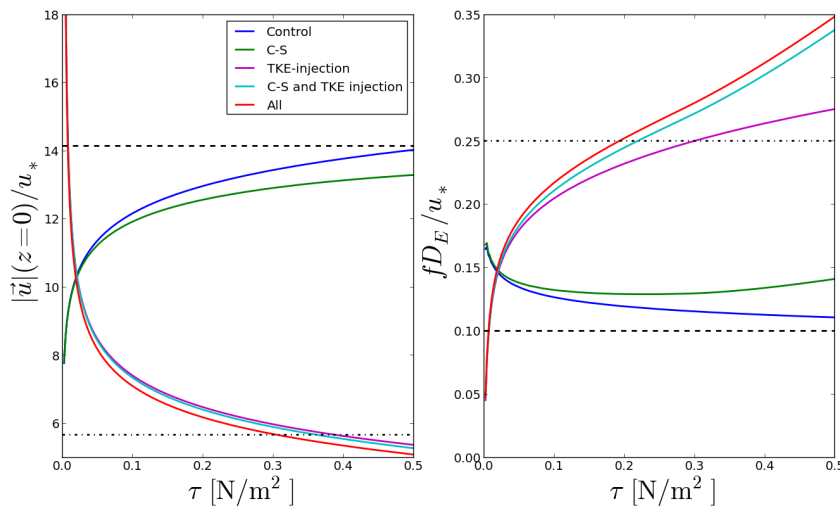

Figure 1. The normalized velocity at the surface as a function of the wind stress (left). Normalized Ekman depth as a function of the wind stress (right). The horizontal black lines represent the solutions predicted by Ekman theory for $X=200$ (dashed line) and for $X=32$ (dash-dotted line).

$400 \mathrm{~m} \mathrm{day}^{-1}$, which could represent oil droplets of different sizes and/or chemical compositions. Notably, $w_{\mathrm{r}}=$ $100 \mathrm{~m} \mathrm{day}^{-1}$ can also represent northeast Arctic cod eggs (Sundby, 1983). For the results shown, the model has been run with the $k-\omega$ closure scheme, which performs well in the near-surface layer (e.g., Umlauf et al., 2003; Jones and Monismith, 2008). For the $k-\omega$ scheme, the exponents in Eq. (17) are given by $p=-1, m=1 / 2, n=-1$. Each experiment has been run as follows: no wave forcing (control); adding only the Coriolis-Stokes force (C-S); adding only the wave-breaking parametrization (TKE-injection); adding both (C-S + TKE-injection); finally, with the Stokes shear production included (all).

\section{Steady-state balances}

We start the model analysis with some idealized experiments to investigate the model behavior for mixing and drift of buoyant particles. We focus on two cases: (i) a case with a rise velocity of $100 \mathrm{~m} \mathrm{day}^{-1}$ and (ii) a case with a rise velocity of $400 \mathrm{~m} \mathrm{day}^{-1}$. We consider a $500 \mathrm{~m}$ deep ocean column (roughly 10 times the Ekman depth) discretized using 300 grid points, with higher resolution close to the surface. To ensure quasi-stationary conditions, the model is initialized from rest and the forcing is increased gradually over a long period (over a year). The time step used in these experiments is $40 \mathrm{~s}$. For these experiments we use $f=1.2 \cdot 10^{-4} \mathrm{~s}^{-1}$ and a density of water $\rho_{w}=1000 \mathrm{~kg} \mathrm{~m}^{-3}$. We consider steadystate conditions with varying wind speed directed along the $x$ axis.

In these idealized experiments the waves will be represented by a Pierson-Moskowitz spectrum (Pierson and Moskowitz, 1964). In principle the stresses should be calculated using the wave spectra as described in Sect. 2.1. However, as we look at a steady-state situation, the flux of mo- 

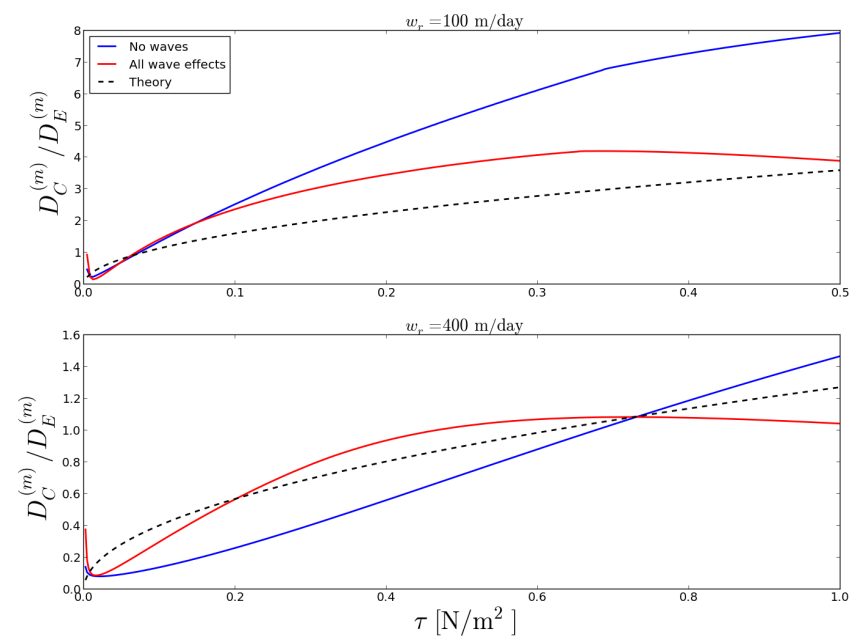

Figure 2. The normalized particle depth $\left(D_{\mathrm{C}}^{(m)} / D_{\mathrm{E}}^{(m)}\right)$ for rise velocities of $w_{\mathrm{r}}=100 \mathrm{mday}^{-1}$ (top panel) and $w_{\mathrm{r}}=400 \mathrm{mday}^{-1}$ (bottom panel). Note the difference in the scale of the axes. The black dashed line is the prediction by Ekman theory (Eq. 28) with $X=12.6$.

mentum and energy passes through the wave field; we therefore use a simple relation such that

$\tau_{x}=\rho_{w} u_{*}^{2}=\rho_{a} C_{D} U_{10}^{2}$,

where $\rho_{a}$ is the air density and $C_{D}$ is the friction coefficient. Here we use $C_{D}=1.5 \cdot 10^{-3}$ and $\rho_{a}=1.2 \mathrm{~kg} \mathrm{~m}^{-3}$. Since we use an empirical wave spectrum, we use $\alpha=100$, the wavebreaking parametrization of Craig and Banner (1994).

\subsection{Scaling analysis}

To provide a tool for analyzing the model results we consider classical Ekman theory valid for a constant eddy viscosity, here denoted by $A_{z}$. The solutions to the classical Ekman problem are then given by (Ekman, 1905)

$u=V_{0} \exp \left(z / D_{\mathrm{E}}\right) \cos \left(\pi / 4+z / D_{\mathrm{E}}\right)$,

$v=V_{0} \exp \left(z / D_{\mathrm{E}}\right) \sin \left(\pi / 4+z / D_{\mathrm{E}}\right)$,

where

$$
\begin{aligned}
V_{0} & =u_{*}^{2} \frac{1}{\sqrt{f A_{z}}}, \\
D_{\mathrm{E}} & =\sqrt{\frac{2 A_{z}}{f}} .
\end{aligned}
$$

For $A_{z}$ it is frequently assumed (e.g., Csanady, 1982) that

$A_{z}=\frac{u_{*}^{2}}{X f}$,

where $X$ is a dimensionless parameter and $u_{*}$ is the (waterside) friction velocity. Using Eq. (23), $V_{0}$ and $D_{\mathrm{E}}$ can be ex-
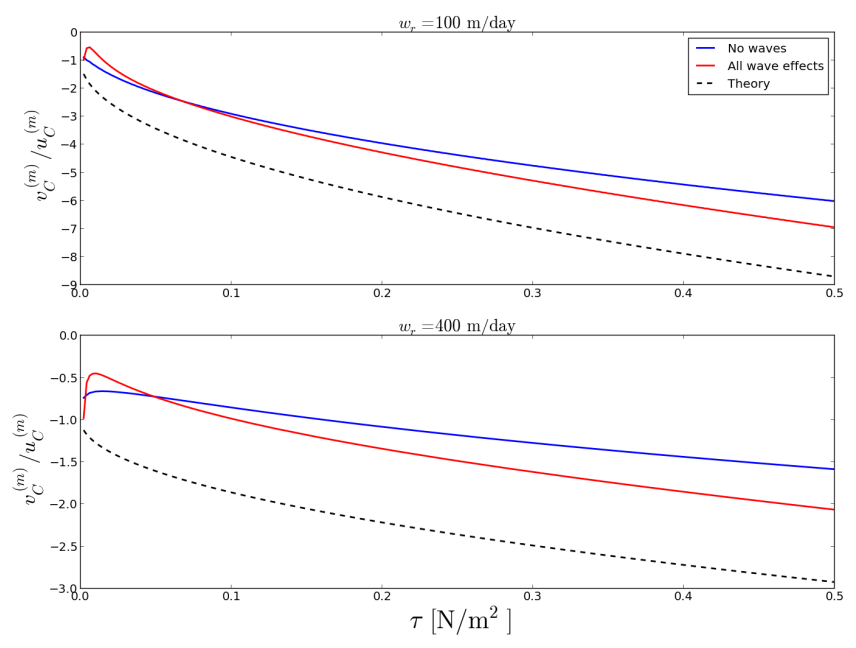

Figure 3. The $y$ velocity scaled by the $x$ velocity as a function of wind stress for rise velocities of $w_{\mathrm{r}}=100 \mathrm{~m} \mathrm{day}^{-1}$ (top panel) and $w_{\mathrm{r}}=400 \mathrm{~m} \mathrm{day}^{-1}$ (bottom panel). The black dashed line is the prediction by Ekman theory (Eq. 30) with $X=12.6$.

pressed as

$$
\begin{aligned}
V_{0} & =\sqrt{X} u_{*}, \\
D_{\mathrm{E}} & =\sqrt{\frac{2}{X}} \frac{u_{*}}{f} .
\end{aligned}
$$

Csanady (1982) finds that $X=200$, while Rascle et al. (2006), who consider wave breaking, use $X=32$. In a steady state, Eq. (19) reduces to

$w_{\mathrm{r}} \frac{\partial}{\partial z} C=\frac{\partial}{\partial z}\left(A_{z} \frac{\partial}{\partial z} C\right)$.

As boundary conditions we assume

$C(z=0)=C_{0}, \quad C(z \rightarrow-\infty)=0$.

The concentration is then given by

$C(z)=C_{0} \exp \left(\frac{z}{D_{\mathrm{C}}}\right)$

where $D_{\mathrm{C}}=\frac{A_{z}}{w_{\mathrm{r}}}$ is a characteristic concentration depth scale. The relation between the particle concentration and Ekman depth scales can then be expressed as

$\frac{D_{\mathrm{C}}}{D_{\mathrm{E}}}=\frac{u_{*}}{w_{\mathrm{r}} \sqrt{2 X}}$,

which implies that the fraction $D_{\mathrm{C}} / D_{\mathrm{E}}$ increases with the wind speed while it decreases with increasing particle rise speed. Interestingly, if both the friction velocity and the rise speed increases a given fraction, the fraction $D_{\mathrm{C}} / D_{\mathrm{E}}$ remains constant. Although we realize that the factor $X$ is important 

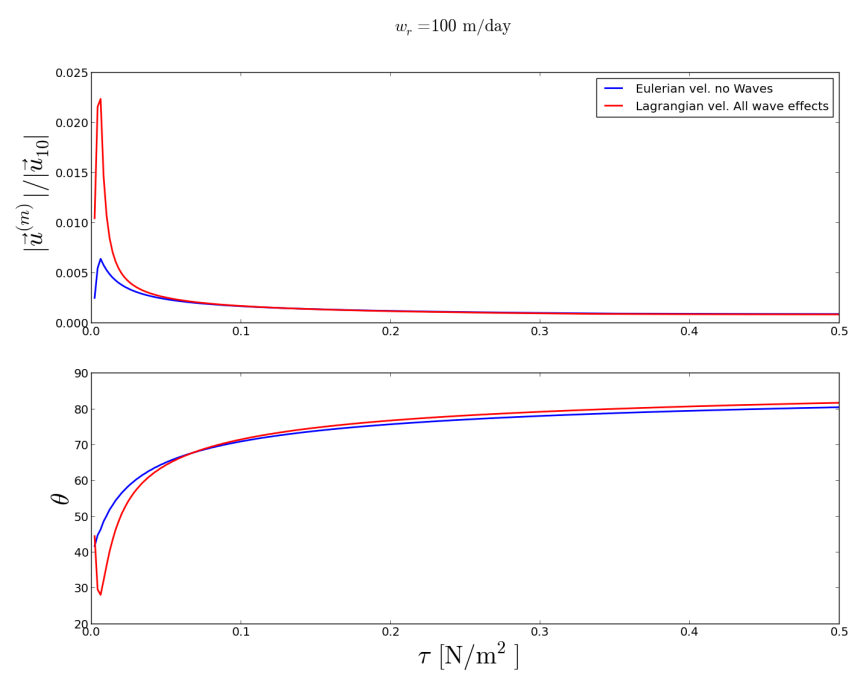

Figure 4. Particle transport speed relative to the wind speed at $10 \mathrm{~m}$ (top) and the angle, $\theta$, between the transport velocity and the wind (bottom). The rise velocity is $w_{\mathrm{r}}=100 \mathrm{~m} \mathrm{day}^{-1}$.

for the ratio, we do not aim at a detailed analysis of the value of $X$ in this study; we have simply introduced the factor to be able to adjust the curves such that a meaningful comparison between model results and scaling analysis can be made.

Another interesting quantity is the effective transport velocity of particles defined as

$\boldsymbol{u}_{\mathrm{C}}=\frac{\int_{-D}^{0}\left(\boldsymbol{u}+\boldsymbol{u}_{\mathrm{S}}\right) C \mathrm{~d} z}{\int_{-D}^{0} C \mathrm{~d} z}$,

where $D$ denotes the ocean depth. For the scaling analysis we assume that $\boldsymbol{u}_{\mathrm{S}}$ is zero (as it is not included in our analytical expressions). Analytical expressions that relate the transport to $D_{\mathrm{C}}$ and $D_{\mathrm{E}}$ can be found; however, here we do not consider these expressions, as they do not provide simple insight into the dynamics of the transport velocity and direction. However, we find a useful relation between the $x$ and $y$ components, $u_{\mathrm{C}}$ and $v_{\mathrm{C}}$, that can be described in simple terms as

$v_{\mathrm{C}} / u_{\mathrm{C}}=-\left(1+2 D_{\mathrm{C}} / D_{\mathrm{E}}\right)$.

We thus find that the transport of particles will have stronger veering when the particle concentration depth scale becomes larger. As an example, for a particle rise velocity of $100 \mathrm{~m} \mathrm{day}^{-1}$ and for a surface stress of roughly $0.05 \mathrm{~N} \mathrm{~m}^{-2}$, we find that $D_{\mathrm{C}}=D_{\mathrm{E}}$ and $v_{\mathrm{C}} / u_{\mathrm{C}}$ increases by a factor of 3 compared to the case when all particles are at the surface. The physical interpretation is simply that for deeper distribution of particles, the transport is dominated by the currents deeper down into the Ekman layer, which in turn has stronger veering.
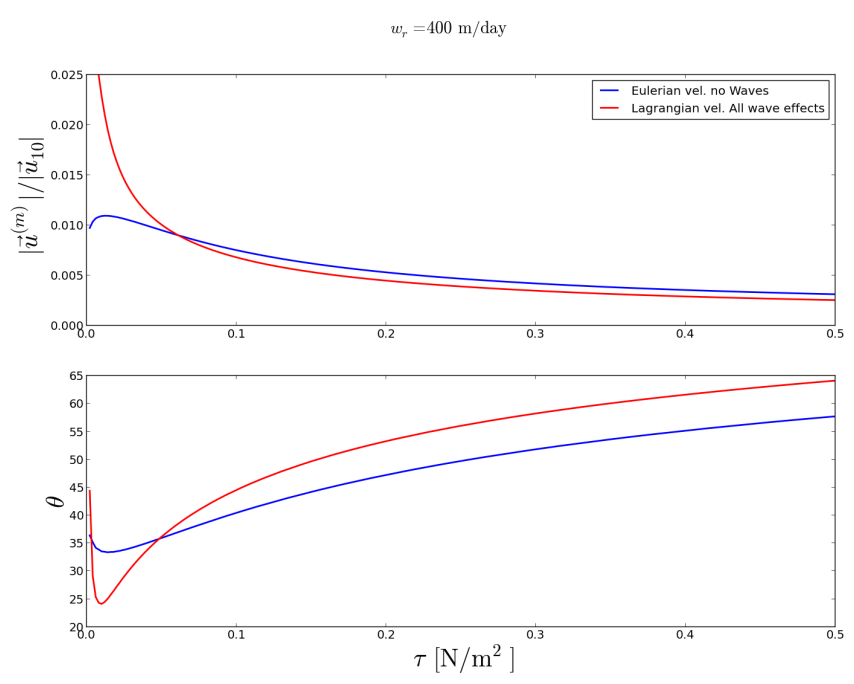

Figure 5. Same as Fig. 4 but for particle rise velocity of 400 m day $^{-1}$.

\subsection{Transport and vertical distribution of particles}

For the evaluation of the model results, we define the Ekman and the characteristic concentration depth scales from the model as

$D_{\mathrm{E}}^{(m)}=\frac{\int_{-D}^{0}|\boldsymbol{u}| \mathrm{d} z}{|\boldsymbol{u}(z=0)|}, \quad D_{\mathrm{C}}^{(m)}=\frac{\int_{-D}^{0} C \mathrm{~d} z}{C(z=0)}$.

The model results for these variables are shown in Fig. 1. Also shown as horizontal lines are the solutions predicted by Eq. (24) for $X=32$ and $X=200$. While the model result approaches the solution $X=200$ in the case when no wave effects are included, the results when wave mixing is included are closer to $X=32$. This difference is consistent with the previous discussion that, without wave effects, $X=200$ has been used (Csanady, 1982), while $X=32$ has been used for the wave breaking case (Craig and Banner, 1994; Rascle et al., 2006). From simple scaling theory in Eq. (24) we expect the velocity at the surface and the Ekman depth to vary approximately linearly with the friction velocity (or the scaled Ekman depth to be constant); however, as seen in Fig. 1, the solutions are far from linear. We also see that the cases with wave breaking are further from the scaling law, suggesting that the additional flux of TKE from waves break the original assumptions in the scaling theory. Figure 1 (right panel), which scales as the square root of the eddy viscosity, suggests that the eddy viscosity may scale differently for the case with TKE-injection as compared to the case without TKE-injection; i.e., Eq. (23) is not an appropriate scale relation in the case of TKE-injection, and this spills over to the relation Eq. (24) that is plotted on the right panel of Fig. (1). The eddy viscosity is important for the derivation of velocity, and the same argument applies to the deviations in this case as well. Thus, the scaling laws and the model deviation from 
the scaling laws provide valuable insight into the dynamics of the system. We especially see that the cases with wave breaking are quite different from the cases without wave breaking and show very different asymptotic behavior. For the normalized characteristic particle depth (i.e., $D_{\mathrm{C}} / D_{\mathrm{E}}$ ), we find that it increases with $u_{*}$ or with the square root of the stress in the scaling analysis. However, taking into account that the turbulent diffusivity is parabolic with depth in a non-stratified ocean, we do expect that the model $D_{\mathrm{C}} / D_{\mathrm{E}}$ should lie below the scaling law when $D_{\mathrm{C}} / D_{\mathrm{E}}$ is smaller than unity, and lie above the scaling law when $D_{\mathrm{C}} / D_{\mathrm{E}}$ is larger than unity. This is illustrated in Fig. 2. Only the cases where the waves are completely neglected and the case with all wave effects are shown. It may be noted that here we have adjusted the value of $X$ such that the scaling law fits the model for roughly $D_{\mathrm{C}} / D_{\mathrm{E}}=1$.

One interesting feature we notice is that for low rise velocities, the particles are mixed very deep, indicating that the eddy viscosity is quite high even below the region where the Reynolds stresses are important (i.e., the Ekman layer depth). This means that the weak turbulent velocities must be compensated with a large mixing length scale. However it should be noted that in more realistic conditions, which are not considered in these idealized experiments, stratification has an effect on mixing by inhibiting vertical diffusion of TKE. Here we have ignored this effect in order to compare the results with the Ekman theory. The theoretical analysis requires that the well-mixed layer should be much deeper than $D_{\mathrm{E}}$ and $D_{\mathrm{C}}$. A factor of 2 can be taken as an example. For momentum, this corresponds to $0.5 u_{*} / f$, i.e, about 2 times the value in Fig. 1 (right panel), or $200 \mathrm{~m}$ for $u_{*}=0.05 \mathrm{~m} \mathrm{~s}^{-1}$. For the rising particle analysis it depends strongly on the rise speed (see Eq. 28); for slow rise speed we may need a factor 5 times the Ekman depth or up to $1000 \mathrm{~m}$ deep mixed layer (thus we expect that these situations will never occur in the real ocean and this parameter regime should be considered with some caution).

From the scaling laws Eqs. (28) and (30) we expect that the mean transport velocity of the particles will veer as we increase the wind stress, and this is clearly seen in Fig. 3. We notice that the model does not have as strong veering as predicted by the scaling law, and this is most likely explained by the fact that the eddy viscosity is far from constant in the model. We see that results are closer for a low rise velocity than for a high rise velocity. This is in agreement with the results of the scaling depths for momentum $\left(D_{\mathrm{E}}\right)$ and particles $\left(D_{\mathrm{C}}\right)$ as discussed earlier. We also see that cases with all wave effects included have a stronger veering in particle drift than the model without waves, consistent with our expectations that waves mix particles deeper and create a stronger veering due to the Coriolis-Stokes force. So far we have mainly considered non-dimensionalized drift velocities, and the translation to real situations requires a dimensionalization of the results. For more accessible results, we plot the drift speed scaled by the wind speed at $10 \mathrm{~m}$ height and

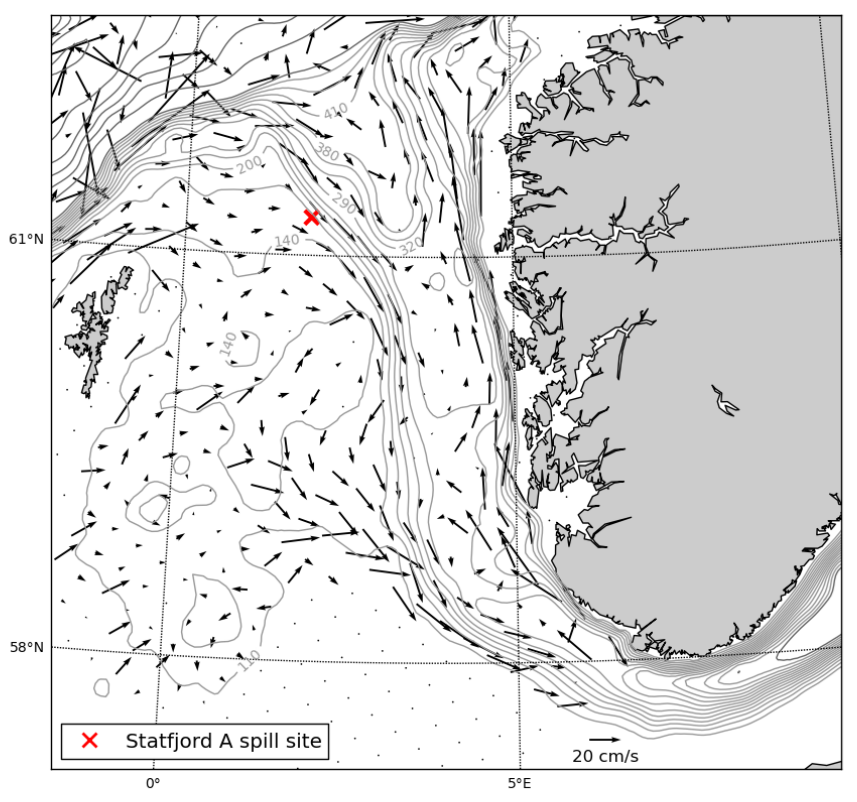

Figure 6. Statfjord A area with bottom contours and currents (daily mean 13 December 2007) at $100 \mathrm{~m}$ depth from SVIM hindcast archive (Lien et al., 2013). The depth at the spill site is approximately $150 \mathrm{~m}$.

the angle $\theta$ between the drift direction and the wind direction in Figs. 4 and 5. When the waves are not included, the total momentum must be contained in the Eulerian current; when the waves are included, the Stokes drift is added. From the mean particle drift it can be seen that in all cases this relation approaches a constant value, similar to the empirical relation (Eq. 1). Since we here consider the transport defined by Eq. (29), which is a depth-averaged quantity, the drift speed is far less than $3 \%$ of the wind speed that is often used in Eq. (1) for surface drift. It should be noted that the drift predicted by the model is also less than the $1 \%$ of the wind speed that was observed by Reed et al. (1994) for wind seas over $6 \mathrm{~m} \mathrm{~s}^{-1}$. However, this may well be due to the fact that in these idealized experiments we have neglected the effect of stratification and that we only consider constant forcing, which is unrealistic for the real ocean. The effects of stratification and changing forcing conditions are included in the realistic case considered in the next section. In agreement with earlier discussion, we also see from Figs. 4 and 5 that the veering increases with increasing wind speed and that cases with all wave effects has stronger veering than the standard model setup. This effect is notably stronger for the more buoyant particles. 


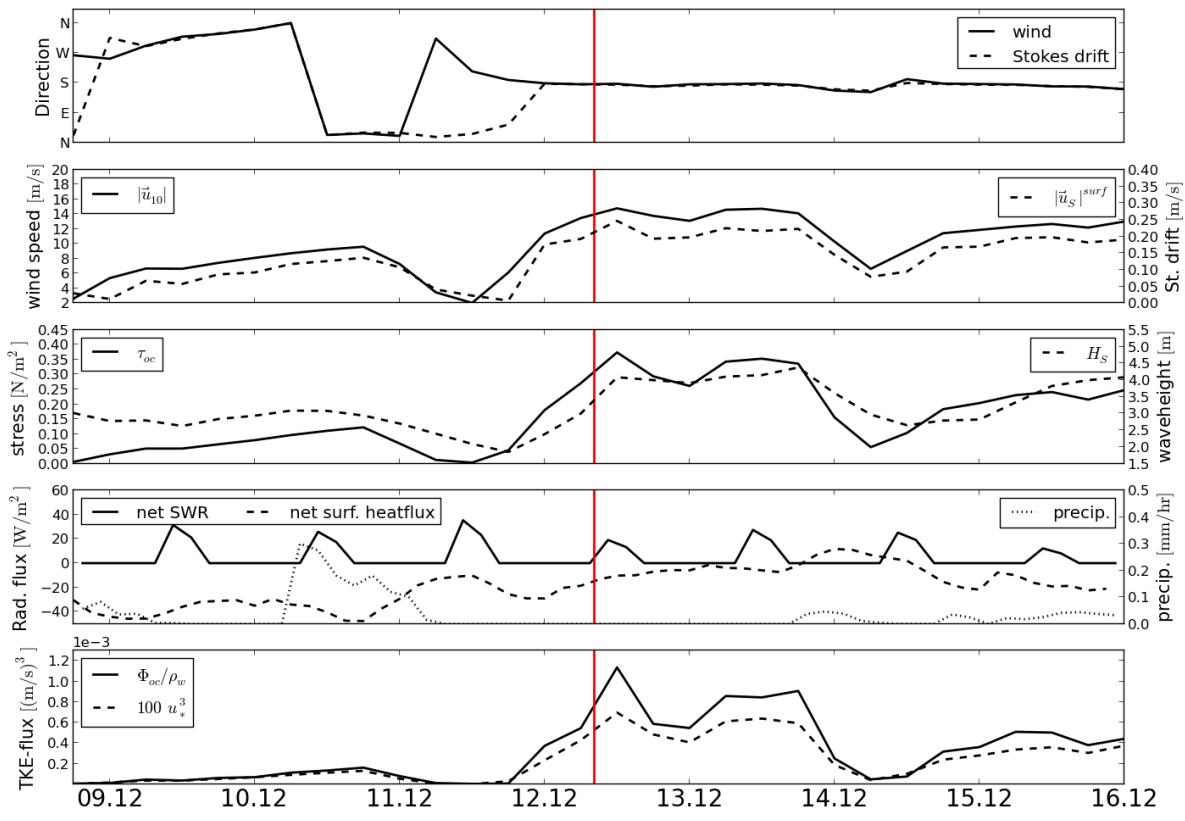

Figure 7. Wind and wave conditions from ERA Interim before, during, and after the Statfjord A oil spill. The incident time of the oil spill is indicated by the vertical red line. From top to bottom, the panels show: wind and Stokes drift direction; wind and Stokes drift magnitude; effective momentum flux to the ocean and the significant wave height; net short-wave and net surface heat flux and precipitation; TKE fluxes into the ocean as calculated from the wave spectrum and from the Craig and Banner (1994) parametrization with $\alpha=100$.

\section{Statfjord A oil spill}

\subsection{Environmental conditions}

The Statfjord A oilfield is located at approximately $61.25^{\circ} \mathrm{N}$, $1.85^{\circ} \mathrm{E}$, about $200 \mathrm{~km}$ off the west coast of Norway. The ocean depth close to the platform is about $150 \mathrm{~m}$, but with rather steep bottom slopes located nearby to the northeast (Fig. 6). This was the site of a large oil spill in December 2007 (Broström et al., 2008). Starting on 12 December 2007 at 08:17 UTC and lasting 20-45 min, an estimated 4400 cubic meters of crude oil was spilled into the ocean from a ruptured loading hose near the platform. Since the wind and wave conditions were quite severe during and after the spill (see Fig. 7), few observations of the oil slick exist. After a few hours the slick was estimated to be $8 \mathrm{~km}$ long and $1 \mathrm{~km}$ wide, and by late afternoon on 12 December its surface area covered an estimated $23 \mathrm{~km}^{2}$. The only observation of the oil slick from an aircraft was made 2 days later on 14 December at 13:48 UTC. Located approximately $16 \mathrm{~km}$ to the east-southeast of the spill site, the slick was then about $10 \mathrm{~km}$ long and $5 \mathrm{~km}$ wide. Relating the drift to the wind during the time at which the oil spill started until the observation gives an estimated speed of $0.5 \%$ of the wind speed at an angle of about $90-120^{\circ}$ to the right.

In order to simulate the net drift of oil, the model was run with a vertical resolution of $0.25 \mathrm{~m}$ and a time step of $20 \mathrm{~s}$. To initialize the model it was gradually spun up from rest over a $24 \mathrm{~h}$ period and run with constant forcing over a sufficiently long period to ensure quasi-steady conditions; it was then restarted about $21 \mathrm{~h}$ prior to the accident with initial temperature and salinity profiles from measurements. For the results in this case study the model was forced with wind, wave, and radiative forcing from the ERA Interim reanalysis (Dee et al., 2011). In Fig. 7 it can be seen that the wind was essentially directed northwards at approximately $15 \mathrm{~m} \mathrm{~s}^{-1}$ for about 2 days following the accident, and the significant wave height $H_{\mathrm{S}}$ was up to $4.5 \mathrm{~m}$. The surface Stokes drift direction and magnitude can also be seen in Fig. 7. From the start of the oil spill to the observation 2 days later there was a coinciding peak in momentum and energy fluxes into the ocean (Fig. 7). Also shown in Fig. 7 are the net shortwave radiation, net heat flux, and precipitation. Since the area is located at $61.25^{\circ} \mathrm{N}$ and the oil spill occurred in December, the shortwave radiation was rather low. For a period before the oil spill there was a net cooling at the surface, leading to destabilization of the water column.

For hydrography we use observations available from the International Council for the Exploration of the Sea (ICES). There are few observations that coincide with the Statfjord A oil spill; the closest to the time before the accident was located approximately $56 \mathrm{~km}$ to the south on 11 December at 11:21 UTC. The first CTD measurement after the observation was close to where the oil was spilled into the ocean (approximately $3 \mathrm{~km}$ east) but about 18 hours after the observation by the overflight. Differences in total heat content imply that the two CTD casts sampled slightly different water masses. Although the observations do not coincide perfectly 

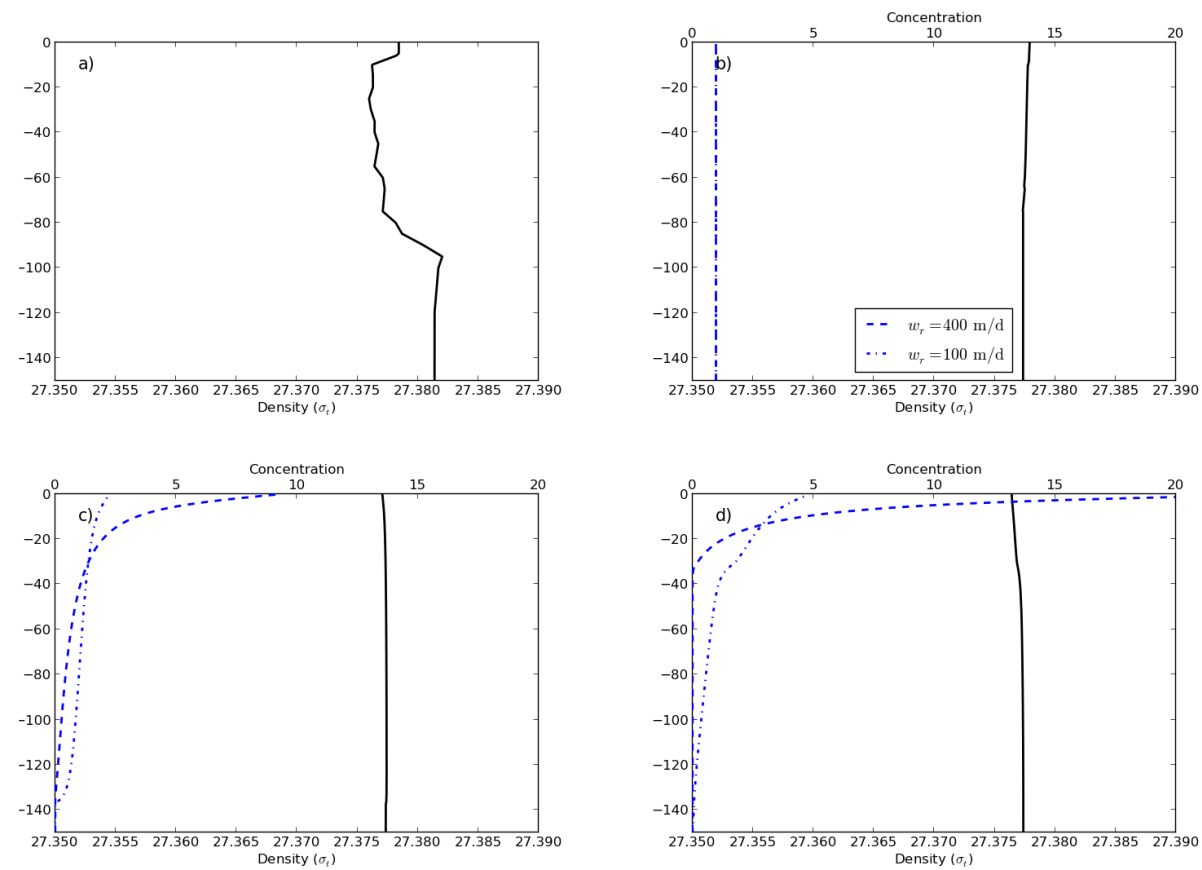

Figure 8. Time evolution of density (black lines) and particle concentration profiles (blue lines): (a) initial density profile (11 December 2007, 11:21 UTC), (b) approximately at the start of the oil spill (12 December 2007, 08:30 UTC), (c) 14 December 2007, 00:00 UTC (d) 14 December 2007, 14:00 UTC. The depth at the spill site is approximately $150 \mathrm{~m}$.

with the oil spill, they show some important characteristics of the conditions during the oil spill. The first CTD cast was used to initialize the model, and the density profile can be seen in Fig. 8a. Typical for the area and time of year, the water masses before the accident were quite well mixed but with a small density gradient, due to more saline water, starting at approximately $80 \mathrm{~m}$ depth (Fig. 8a). The CTD cast after the observations shows almost no stratification, and the results from the model indicate that this had already occurred by the time the oil spill had started (Fig. 8b). Concentration profiles for particles wtih $w_{\mathrm{r}}=100 \mathrm{~m}$ day $^{-1}$ and $w_{\mathrm{r}}=400 \mathrm{~m}$ day $^{-1}$ are also shown in Fig. 8. Since the oil was spilled into the ocean from a loading hose that was located below the surface, the exact depth at which the oil was spilled is unknown. However, the oil was probably released into the ocean at various depths during the spill, and we consider initializing the spill with a concentration evenly distributed over the water column (Fig. 8b) to be realistic. Prevailing wind and wave conditions led to deeper mixing of the particles until approximately 14 December at 00:00 UTC (Fig. 8b), when the calmer conditions caused more and more particles to resurface until the observation about 14 hours later (Fig. 8d).

In this area there is a branch of Atlantic water flowing along the bottom contours (e.g., Albretsen and Røed, 2010, Fig. 9). To make an estimate of this current component we have used the model hindcast archive described by Lien et al. (2013). The approximate magnitude and direction is illustrated by the daily mean at $100 \mathrm{~m}$ depth on 13 Decem- ber 2007 in Fig. 6. While the wind-driven current and the Stokes drift decay with depth, the topographic current extends over most of the water column; thus the relative importance of the different current components on the transport depends on the depth of the particles.

\subsection{Transport and vertical distribution of particles}

An example of how the wave effects modify the Eulerian currents can be seen in Fig. 9. As can be expected from previous studies (e.g., Polton et al., 2005), the Coriolis-Stokes force turns the current further to the right. In all cases when wave effects are included, the sea-state-dependent momentum flux is calculated using Eq. (4). The wave-breaking parametrization has a large impact on the velocities close to the surface, while the Stokes shear production in this case is less important for the upper ocean mixing. When all wave effects are included, the surface current speed is reduced by more than $50 \%$.

Comparing concentration profiles for the cases with and without waves (Fig. 10), it can be seen that the waves increase the mixing. In general, the increased mixing by the waves leads to a higher concentration of particles deeper down in the water masses. Hence, the currents deeper down become more important for the net transport when waveinduced mixing is included. Furthermore, it can be seen that the wave effects are more important for higher rise velocities $w_{\mathrm{r}}$; for low $w_{\mathrm{r}}$ the shear turbulence is sufficient to mix the particles down, hence profiles with and without waves 

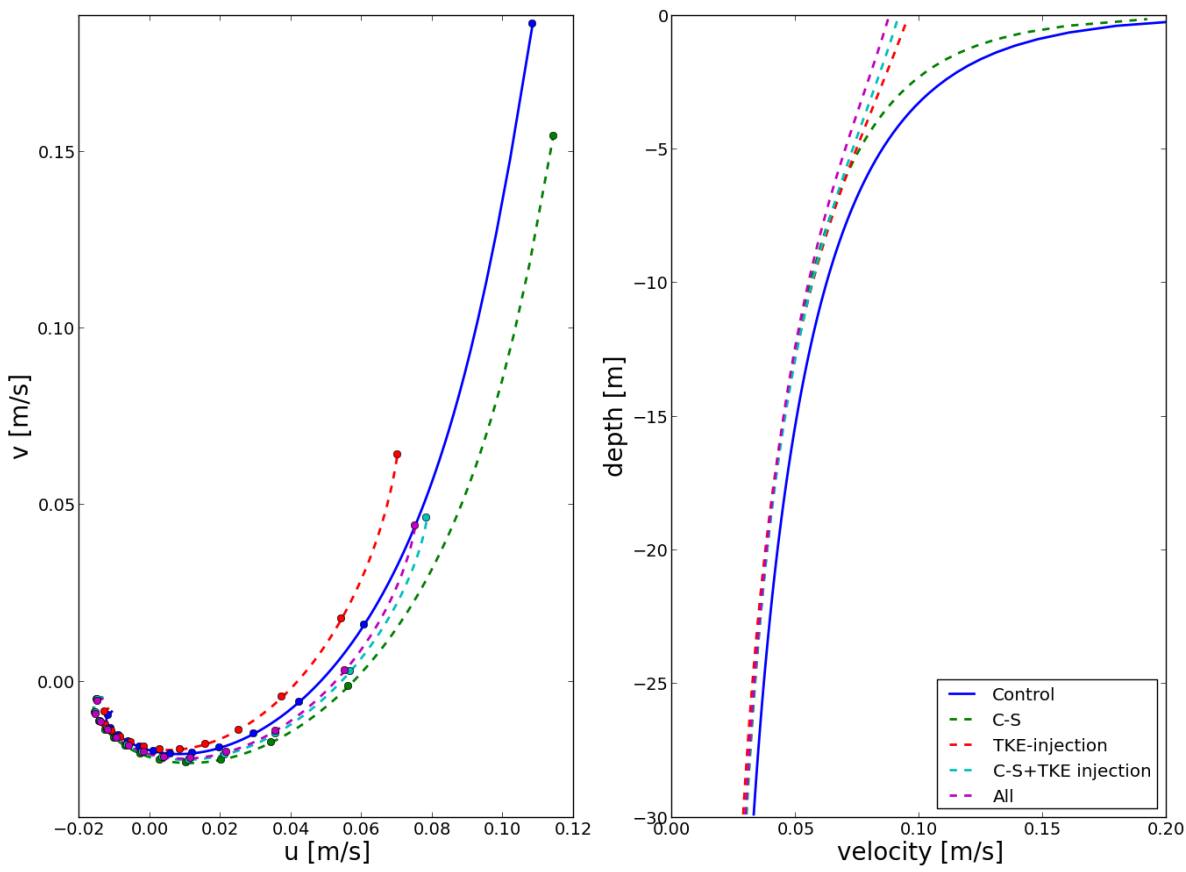

Figure 9. Hodograph (left: marked for every $10 \mathrm{~m}$ ), and depth profile (right: upper $30 \mathrm{~m}$ ) of the wind-driven Eulerian current approximately $12 \mathrm{~h}$ after oil spill (12 December 2007, 21:00 UTC).
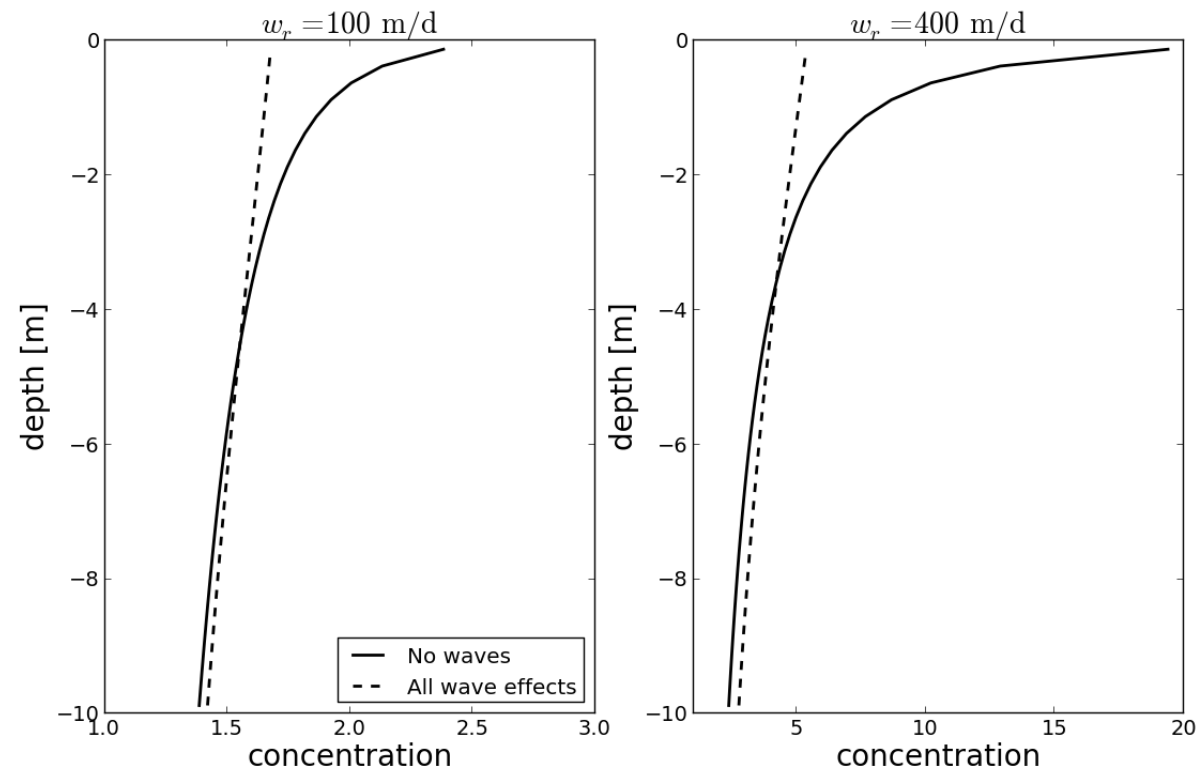

Figure 10. Concentration profile approximately $12 \mathrm{~h}$ after the oil spill (12 December 2007, 21:00 UTC) for particles with rise velocity of $100 \mathrm{~m} \mathrm{day}^{-1}$ (left) and $400 \mathrm{~m} \mathrm{day}^{-1}$ (right). Note the difference in scale of the $x$ axis.

are more similar. While the wind and wave conditions cause strong mixing at the beginning of the accident, the calmer conditions from approximately 40 hours into the spill cause more and more particles to resurface until the time of the observation (about 53 hours after the spill).

With the current $\boldsymbol{u}$ and the relative concentration profiles $C(z)$ from the mixing model, the background current $\boldsymbol{u}_{B G}$ estimated from the model hindcast of Lien et al. (2013), and the Stokes drift $\boldsymbol{u}_{\mathrm{S}}$ calculated from the wave spectra, a transport velocity similar to Eq. (29) can be defined as

$\boldsymbol{u}^{(m)}=\frac{\int_{-D}^{0}\left(\boldsymbol{u}+\boldsymbol{u}_{B G}+\boldsymbol{u}_{\mathrm{S}}\right) C(z) \mathrm{d} z}{\int_{-D}^{0} C(z) \mathrm{d} z}$. 


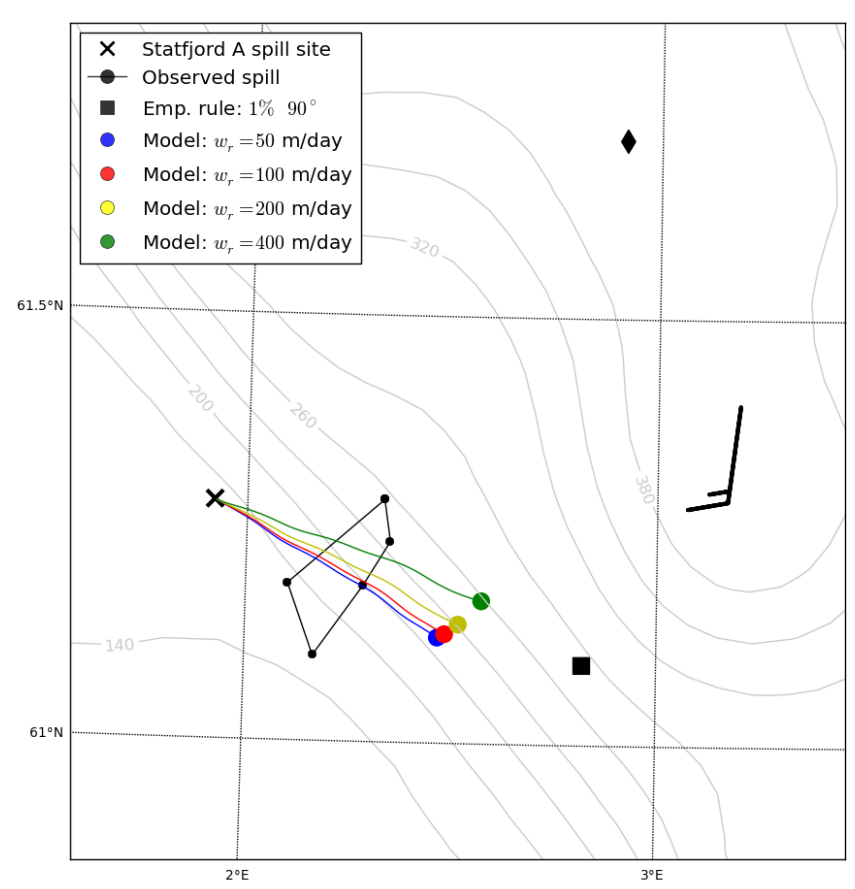

Figure 11. Mean location of oil predicted by the model for different rise velocities of the particles. The model is initialized with particle concentrations evenly spread in the water column. Also shown is the mean locations predicted by empirically based relations between the drift and the mean wind vector. The observed oil slick is shown with coordinates from observation (14 December 2007 13:48 UTC) connected with lines.

Using this, the transport of particles by the model can be compared with the observation, and the result is shown in Fig. 11. While the direction of the predicted oil spill coincides quite nicely with the observation, the modeled drift seems to be too fast. Depending on the rise velocities, the end locations from the model spread in a southwest-northeast direction similar to the observed oil slick. Also shown in Fig. 11 are two different end locations predicted when using the empirically based relation (Eq. 1). One is the expected drift of oil at the surface with $3 \%$ of the wind speed at an angle of $15^{\circ}$ to the right (Reed et al., 1999; Hackett et al., 2006), while the other is based on observations that oil mixed below the surface has a mean drift of $1 \%$ of the wind speed with an angle of $90^{\circ}$ to the right (Reed et al., 1994). Clearly the latter case is the more realistic for the Statfjord A oil spill since the wind speed was well above the $6 \mathrm{~m} \mathrm{~s}^{-1}$ threshold found by Reed et al. (1994) (Fig. 7). Consistent with the qualitative analysis by Reed et al. (1994), oil was probably quickly mixed below the surface and, as Fig. 8 indicates, large amounts remained so for the majority of the time until the observation (after a period of calmer conditions).

To illustrate the sensitivity of the model to the depth at which the particles are released, a run with the oil released at the surface is compared with a run where the oil has been

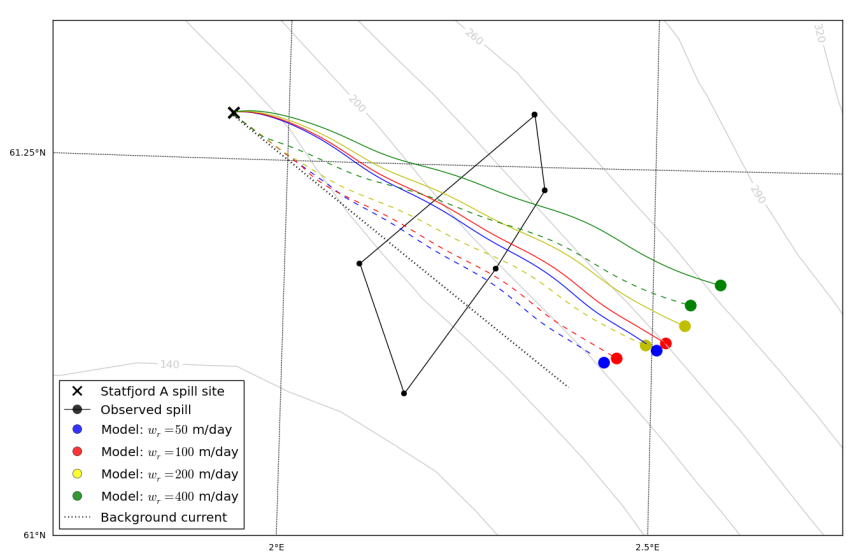

Figure 12. Mean location of oil predicted by the model when the oil is released at the surface (solid lines) and at the bottom (dashed lines). Also included (black dotted line) is the net drift component from the background current.

released at the bottom in Fig. 12. Although the initial drift directions of the bottom- and surface-released particles are quite different, the strong mixing results in similar trajectories after a time (depending on the rise speed). The less buoyant particles are affected more strongly by the release depth, and the end locations of particles with rise speeds of $50 \mathrm{~m} \mathrm{day}^{-1}$ are located approximately $4 \mathrm{~km}$ apart. The background current has a significant effect on both the modeled drift using Eq. (32) and when using the empirical relation (Eq. 1). On average, the magnitude of $\boldsymbol{u}_{\mathrm{BG}}$ is about $50 \%$ of the surface value of the combined wind-driven and Stokes drift components. The net drift due to the background current, i.e., when neglecting $\boldsymbol{u}$ and $\boldsymbol{u}_{\mathrm{S}}$ in Eq. (32), is also shown in Fig. 12. Here we consider the background current to be the least known, but a more detailed analysis is beyond the scope of the present study. Shear dispersion is not included in these experiments. In the Statfjord A case, the difference between the average drift in the upper $5 \mathrm{~m}$ is about $25 \%$ higher than the average drift between 5 and $10 \mathrm{~m}$ during the first $24 \mathrm{~h}$ following the accident. The difference in results for different rise velocities (Fig. 11) also indicates to some extent the potential role of shear dispersion. We emphasize, however, that our ultimate goal is to use a similar mixing scheme in a full 3-D model, which will likely produce more realistic results. We therefore do not wish to further parametrize the effect of shear dispersion here.

\section{Concluding remarks}

The results from the steady-state analysis and the Statfjord A oil spill case indicate that wave-breaking parametrization is the most influential wave effect for the mixing and transport of buoyant particles. In the Statfjord A case presented above, the increased mixing is mainly a result of the injection of TKE through the boundary condition (Eq. 15). Wave- 
breaking parametrizations like the one presented in this study are justified by measurements of increased levels of dissipation rate, $\varepsilon$, beneath breaking waves (e.g., Agrawal et al., 1992). Such observations have led to several studies proposing scaling laws of $\varepsilon$ other than the classic law of the wall (e.g., Anis and Moum, 1995; Terray et al., 1996; Huang and Qiao, 2010). Observations in the mixed layer using a freerising profiler match the law-of-the-wall scaling quite well in some cases; however, general agreement is found with the Langmuir turbulence scaling of Belcher et al. (2012), provided the vertical scale is given by the mixing layer depth rather than the mixed layer depth (Sutherland et al., 2013, 2014). The scaling suggested by Huang and Qiao (2010) has recently been questioned on physical grounds by Kantha et al. (2014).

The drift of oil in the Statfjord A case is similar to two oil release experiments in 1991, which are two out of four experiments considered by Reed et al. (1994). In those cases the oil moved with a mean speed of about $1 \%$ of the wind speed, virtually $90^{\circ}$ to the right of the wind direction; a qualitative explanation is given by Reed et al. (1994). During the Statfjord $\mathrm{A}$ accident the mean drift of the oil was significantly slower relative to the wind at about $0.5 \%$ of the wind speed and slightly further deflected away from the wind direction. This difference may in part be due to higher wind speed during the Statfjord A oil spill, which led to increased mixing.

Although the deflection and decrease in drift is partly due to strong ocean currents in the area, the results from the Statfjord A case show that the waves play a significant role in the drift. Our results indicate that the most important waveinduced mechanism for the drift is the injection of TKE from breaking waves. The increased mixing of particles into the water column results in a slower drift veering towards the right (Northern Hemisphere), and the background currents become more important. The theory described contributes physical understanding of the observed drift, and the model results show some of the potential effect of including waves in drift modeling.

In the turbulence model applied in this study, the Stokes drift shear contributes in the TKE and length-scaledetermining equations. It has been suggested by Harcourt (2013) that, in order to include Langmuir turbulence in a second-order model, it is also necessary to modify the stability functions. However, the model by Harcourt (2013) does not include the effect of wave breaking. Since we here consider the drift of buoyant particles where the near surface dynamics are important, we have chosen to include wave breaking and use simpler stability functions. An interesting topic for future work would be to study particle drift in models with a more elaborate representation of Langmuir turbulence, especially for cases with more stratification and/or neutrally buoyant particles. In this study we have considered a twoequation model; however, it should be noted that a firstorder model that includes both the effect of wave breaking and Langmuir turbulence has been proposed by McWilliams et al. (2012).

Wave conditions in Norwegian waters are quite rough, especially during winter, with January mean significant offshore wave heights exceeding $3 \mathrm{~m}$ in most of the Norwegian Sea and the northern North Sea (Reistad et al., 2011). Estimates of air-sea momentum and energy fluxes are typically rapidly fluctuating with wave effects being important: for sea-state-dependent momentum fluxes we often see differences of $20-50 \%$ compared to traditional parametrizations (e.g., Röhrs et al., 2012). Belcher et al. (2012) also identify Norwegian waters as particularly problematic in modeling mixed layer depths, with errors ranging between 50 and $100 \%$ (their Fig. 1). In addition, the water column is often weakly stratified and without significant diurnal variation, indicating that the development of the mixed layer may be largely controlled by sea-state-dependent momentum and energy fluxes and wave-induced turbulence. Unfortunately we lack long time series of co-located meteorological, wave, current, and hydrographic measurements at these high latitudes. Such measurements would allow us to study the importance of surface waves for the upper ocean mixing in the high north and in particular the usefulness of recently suggested parametrizations for Langmuir turbulence in more detail (e.g., Kantha and Clayson, 2004; Carniel et al., 2005; McWilliams et al., 2012; Harcourt, 2013).

Acknowledgements. We gratefully acknowledge financial support from the Research Council of Norway through grants 196438 (BIOWAVE), 20754 (OILWAVE), and the European Union/FP7 through grant 284455 (MyWave).

Edited by: M. Hoppema

\section{References}

Agrawal, Y. C., Terray, E. A., Donelan, M. A., Hwang, P. A., Williams, A. J., Drennan, W., Kahma, K., and Kitaigorodskii, S.: Enhanced dissipation of kinetic energy beneath surface waves, Nature, 359, 219-220, doi:10.1038/359219a0, 1992.

Albretsen, J. and Røed, L. P.: Decadal long simulations of mesoscale structures in the northern North Sea/Skagerrak using two ocean models, Ocean Dynam., 60, 933-955, 2010.

Anis, A. and Moum, J. N.: Surface Wave-Turbulence Interactions: Scaling $\epsilon(z)$ near the Sea Surface, J. Phys. Oceanogr., 25, 2025 2045, 1995.

Ardhuin, F. and Jenkins, A. D.: On the interaction of surface waves and upper ocean turbulence., J. Phys. Oceanogr., 36, 551-557, doi:10.1175/JPO2862.1, 2006.

Belcher, S. E., Grant, A. L., Hanley, K. E., Fox-Kemper, B., Van Roekel, L., Sullivan, P. P., Large, W. G., Brown, A., Hines, A., Calvert, D., Rutgersson, A., Pettersson, H., Bidlot, J.-R., Janssen, P. A. E. M., and Polton, J. A.: A global perspective on Langmuir turbulence in the ocean surface boundary layer, Geophys. Res. Lett., 39, L18605, doi:10.1029/2012GL052932, 2012. 
Broström, G., Carrasco, A., Hackett, B., and Saetra, Ø.: Using ECMWF products in global marine drift forecasting services, ECMWF Newsletter, 118, 16-20, 2008.

Broström, G., Christensen, K. H., Drivdal, M., and Weber, J. E. H.: Note on Coriolis-Stokes force and energy, Ocean Dynam., 64, 1039-1045, 2014.

Burchard, H., Flöser, G., Staneva, J. V., Badewien, T. H., and Riethmüller, R.: Impact of density gradients on net sediment transport into the Wadden Sea, J. Phys. Oceanogr., 38, 566-587, 2008.

Carniel, S., Sclavo, M., Kantha, L., and Clayson, C.: Langmuir cells and mixing in the upper ocean, Nuovo Cimento C Geophysics Space Physics C, 28, 33, 2005.

Carniel, S., Warner, J. C., Chiggiato, J., and Sclavo, M.: Investigating the impact of surface wave breaking on modeling the trajectories of drifters in the northern Adriatic Sea during a wind-storm event, Ocean Model., 30, 225-239, 2009.

Craig, P. D. and Banner, M. L.: Modelling Wave-Enhanced Turbulence in the Ocean Surface Layer, J. Phys. Oceanogr., 24, 25462559, 1994.

Craik, A.: The generation of Langmuir circulations by an instability mechanism, J. Fluid Mech., 81, 209-223, 1977.

Csanady, G. T.: Circulation in the coastal ocean, vol. 2, Springer, Netherlands, 1982.

d'Alessio, S., Abdella, K., and McFarlane, N.: A new second-order turbulence closure scheme for modeling the oceanic mixed layer, J. Phys. Oceanogr., 28, 1624-1641, 1998.

D'Asaro, E. A.: Turbulence in the upper-ocean mixed layer, Annu. Rev. Mar. Sci., 6, 101-115, 2014.

D’Asaro, E., Thomson, J., Shcherbina, A., Harcourt, R., Cronin, M., Hemer, M., and Fox-Kemper, B.: Quantifying upper ocean turbulence driven by surface waves, Geophys. Res. Lett., 41, 102-107, 2014.

Dee, D. P., Uppala, S. M., Simmons, A. J., Berrisford, P., Poli, P., Kobayashi, S., Andrae, U., Balmaseda, M. A., Balsamo, G., Bauer, P., Bechtold, P., Beljaars, A. C. M., van de Berg, L., Bidlot, J., Bormann, N., Delsol, C., Dragani, R., Fuentes, M., Geer, A. J., Haimberger, L., Healy, S. B., Hersbach, H., Holm, E. V., Isaksen, L., Kallberg, P., Kohler, M., Matricardi, M., McNally, A. P., Monge-Sanz, B. M., Morcrette, J.-J., Park, B.-K., Peubey, C., de Rosnay, P., Tavolato, C., Thepaut, J.-N., and Vitart, F.: The ERA-Interim reanalysis: configuration and performance of the data assimilation system, Q. J. R. Meteor. Soc., 137, 553-597, 2011.

Ekman, V. W.: On the influence of the earth's rotation on ocean currents, Ark. Mat. Astr. Fys., 2, 1-53, 1905.

Gemmrich, J. R., Mudge, T., and Polonichko, V.: On the energy input from wind to surface waves, J. Phys. Oceanogr., 24, 24132417, 1994.

Gemmrich, J. R. and Farmer, D. M.: Observations of the scale and occurrence of breaking surface waves, J. Phys. Oceanogr., 29, 2595-2606, 1999.

Gemmrich, J. R. and Farmer, D. M.: Near-surface turbulence in the presence of breaking waves., J. Phys. Oceanogr., 34, doi:10.1175/1520-0485(2004)034<1067:NTITPO>2.0.CO;2, 2004.

Grant, A. L. M. and Belcher, S. E.: Characteristics of Langmuir Turbulence in the Ocean Mixed Layer, J. Phys. Oceanogr., 39, 1871-1887, 2009.
Hackett, B., Breivik, Ø., and Wettre, C.: Forecasting the Drift of Objects and Substances in the Ocean, in: Ocean Weather Forecasting, edited by: Chassignet, E. and Verron, J., 507-523, Springer, the Netherlands, doi:10.1007/1-4020-4028-8_23, 2006.

Hackett, B., Comerma, E., Daniel, P., and Ichikawa, H.: Marine pollution monitoring and prediction, Oceanography, 22, 168-175, 2009.

Harcourt, R. R.: A Second-Moment Closure Model of Langmuir Turbulence, J. Phys. Oceanogr., 43, 673-697, 2013.

Harcourt, R. R. and D'Asaro, E. A.: Large-eddy simulation of langmuir turbulence in pure wind seas, J. Phys. Oceanogr., 38, 15421562, 2008.

Huang, C. J. and Qiao, F.: Wave-turbulence interaction and its induced mixing in the upper ocean, J. Geophys. Res.-Oceans, 115, C04026, doi:10.1029/2009JC005853, 2010.

James, I.: Modelling pollution dispersion, the ecosystem and water quality in coastal waters: a review, Environ. Modell. Softw., 17, 363-385, 2002.

Janssen, P. A. E. M.: Ocean wave effects on the daily cycle in SST, J. Geophys. Res., 117, C00J32, doi:10.1029/2012JC007943, 2012.

Jenkins, A. D.: The use of a wave prediction model for driving a near-surface current model, Deutsche Hydrografische Zeitschrift, 42, 133-149, doi:10.1007/BF02226291, 1989.

Johansen, Ø.: DeepBlow - a Lagrangian Plume Model for Deep Water Blowouts, Spill Sci. Technol. B., 6, 103-111, 2000.

Jones, N. L. and Monismith, S. G.: Modeling the influence of wave-enhanced turbulence in a shallow tide-and winddriven water column, J. Geophys. Res.-Oceans, 113, C03009, doi:10.1029/2007JC004246, 2008.

Kantha, L. and Clayson, C. A.: On the effect of surface gravity waves on mixing in the oceanic mixed layer, Ocean Model., 6, 101-124, 2004.

Kantha, L., Tamura, H., and Miyazawa, Y.: Comment on "Waveturbulence interaction and its induced mixing in the upper ocean" by Huang and Qiao, J. Geophys. Res.-Oceans, 119, 1510-1515, doi:10.1002/2013JC009318, 2014.

Komen, G., Caveleri, L., Donelan, M., Hasselmann, K., and Janssen, P. A. E. M.: Dynamics and modelling of ocean waves, Cambridge University Press, Cambridge CB2 2RU, UK, 1994.

Kukulka, T., Plueddemann, A. J., Trowbridge, J. H., and Sullivan, P. P.: Rapid mixed layer deepening by the combination of Langmuir and shear instabilities: A case study, J. Phys. Oceanogr., 40, 2381-2400, 2010.

Leibovich, S.: The form and dynamics of Langmuir circulations, Annu. Rev. Fluid Mech., 15, 391-427, 1983.

Lien, V. S., Gusdal, Y., Albretsen, J., Melsom, A., and Vikebø, F. B.: Evaluation of a Nordic Seas $4 \mathrm{~km}$ numerical ocean model hindcast archive (SVIM), 1960-2011, Tech. Rep. 7, Institute of marine research, Bergen, Norway, available at: http:// www.imr.no/filarkiv/2014/01/fh_7-2013_swim_til_web.pdf (last access: 30 March 2014), Fisken og Havet, 2013.

McWilliams, J. C., Sullivan, P., and Moeng, C.-H.: Langmuir turbulence in the ocean, J. Fluid Mech., 334, 1-30, 1997.

McWilliams, J. C., Huckle, E., and Liang, J.-H.: The Wavy Ekman Layer: Langmuir Circulations, Breaking Waves, and Reynolds Stress, J. Phys. Oceanogr., 42, 1793-1816, 2012.

Pierson, W. J. and Moskowitz, L.: A proposed spectral form for fully developed wind seas based on the similarity theory of SA Kitaigorodskii, J. Geophys. Res., 69, 5181-5190, 1964. 
Polton, J. A., Lewis, D. M., and Belcher, S. E.: The Role of WaveInduced Coriolis-Stokes Forcing on the Wind-Driven Mixed Layer, J. Phys. Oceanogr., 35, 444-457, doi:10.1175/JPO2701.1, 2005.

Rascle, N. and Ardhuin, F.: Drift and mixing under the ocean surface revisited: Stratified conditions and model-data comparisons, J. Geophys. Res., 114, C02016, doi:10.1029/2007JC004466, 2009.

Rascle, N., Ardhuin, F., and Terray, E. A.: Drift and mixing under the ocean surface: A coherent one-dimensional description with application to unstratified conditions, J. Geophys. Res.-Oceans, 111, 2156-2202, doi:10.1029/2005JC003004, 2006.

Rascle, N., Chapron, B., Ardhuin, F., and Soloviev, A.: A note on the direct injection of turbulence by breaking waves, Ocean Model., 70, 145-151, doi:10.1016/j.ocemod.2012.09.001, 2012.

Reed, M., Turner, C., and Odulo, A.: The role of wind and emulsification in modelling oil spill and surface drifter trajectories, Spill Sci. Technol. B., 1, 143-157, 1994.

Reed, M., Johansen, Ø., Brandvik, P. J., Daling, P., Lewis, A., Fiocco, R., Mackay, D., and Prentki, R.: Oil Spill Modeling towards the Close of the 20th Century: Overview of the State of the Art, Spill Sci. Technol. B., 5, 3-16, doi:10.1016/S13532561(98)00029-2, 1999.

Reistad, M., Breivik, Ø., Haakenstad, H., Aarnes, O. J., Furevik, B. R., and Bidlot, J.-R.: A high-resolution hindcast of wind and waves for the North Sea, the Norwegian Sea, and the Barents Sea, J. Geophys. Res.-Oceans, 116, C05019, doi:10.1029/2010JC006402, 2011.

Röhrs, J., Christensen, K. H., Hole, L. R., Broström, G., Drivdal, M., and Sundby, S.: Observation-based evaluation of surface wave effects on currents and trajectory forecasts, Ocean Dynam., 62, 1519-1533, 2012.

Saetra, Ø., Albretsen, J., and Janssen, P. A. E. M.: Sea-StateDependent Momentum Fluxes for Ocean Modeling, J. Phys. Oceanogr., 37, 2714-2725, 2007.

Schumann, U. and Gerz, T.: Turbulent mixing in stably stratified shear flows, J. Appl. Meteorol., 34, 33-48, 1995.

Skyllingstad, E. D. and Denbo, D. W.: An ocean large-eddy simulation of Langmuir circulations and convection in the surface mixed layer, J. Geophys. Res., 100, 8501-8522, 1995.
Soloviev, A. and Lukas, R.: Observation of wave-enhanced turbulence in the near-surface layer of the ocean during TOGA COARE, Deep-Sea Res. Pt. I, 50, 371-395, 2003.

Sundby, S.: A one-dimensional model for the vertical distribution of pelagic fish eggs in the mixed layer, Deep-Sea Res. Pt. I, 30 , 645-661, 1983.

Sutherland, G., Christensen, K. H., and Ward, B.: Evaluating Langmuir turbulence parameterizations in the ocean surface boundary layer, J. Geophys. Res.-Oceans, 199, 1899-1910, doi:10.1002/2013JC009537, 2014.

Sutherland, G., Ward, B., and Christensen, K. H.: Wave-turbulence scaling in the ocean mixed layer, Ocean Sci., 9, 597-608, doi:10.5194/os-9-597-2013, 2013.

Terray, E. A., Donelan, M. A., Agrawal, Y. C., Drennan, W. M., Kahma, K. K., Williams, A. J., Hwang, P. A., and Kitaigorodskii, S. A.: Estimates of kinetic energy dissipation under breaking waves, J. Phys. Oceanogr., 26, 792-807, doi:10.1175/15200485(1996)026<0792:EOKEDU>2.0.CO;2, 1996.

Umlauf, L. and Burchard, H.: A generic length-scale equation for geophysical turbulence models, J. Mar. Res., 61, 235-265, 2003.

Umlauf, L. and Burchard, H.: Second-order turbulence closure models for geophysical boundary layers. A review of recent work, Cont. Shelf Res., 25, 795-827, 2005.

Umlauf, L., Burchard, H., and Hutter, K.: Extending the k- $\omega$ model towards oceanic applications, Ocean Model., 5, 195-218, 2003.

Ursell, F.: On the theoretical form of ocean swell. On a rotating earth, Mon. Not. R. Astron. Soc., 6, 1-8, 1950.

Warner, J. C., Sherwood, C. R., Arango, H. G., and Signell, R. P.: Performance of four turbulence closure models implemented using a generic length scale method, Ocean Model., 8, 81-113, 2005.

Weber, J. E. H.: A note on mixing due to surface wave breaking, J. Geophys. Res.-Oceans, 113, C11009, doi:10.1029/2008JC004758, 2008.

Weber, J. E. H., Broström, G., and Saetra, Ø.: Eulerian versus Lagrangian Approaches to the Wave-Induced Transport in the Upper Ocean, J. Phys. Oceanogr., 36, 2106-2118, 2006. 